Pot ent $i$ al associ at i on of byst ander-pat i ent rel at i onshi $p$ wi th byst ander response and pat i ent survival in dayt i me out-of-hospi tal cardi ac arrest

\begin{tabular}{|l|l|}
\hline 著者 & $\begin{array}{l}\text { Tanaka Yoshi o, Neda Tet suo, Kami kur a } \\
\text { Takahi sa, N shi Tai ki, On Wat ar u, Hashi not o } \\
\text { Nasaaki, Sakagam Sat or u, I naba Hi deo }\end{array}$ \\
\hline $\begin{array}{l}\text { j our nal or } \\
\text { publ i cat } \mathrm{i} \text { on ti t l e }\end{array}$ & Resusci t at i on \\
\hline vol ume & 86 \\
\hline page $r$ ange & $74-81$ \\
\hline year & $2015-01-01$ \\
\hline URL & ht t p: //hdl . handl e. net /2297/40723 \\
\hline
\end{tabular}




\section{Potential Association of Bystander-Patient Relationship with Bystander Response and Patient Survival in Daytime Out-of-Hospital Cardiac Arrest}

Yoshio Tanaka, MD, $\mathrm{PhD}^{1,2}$; Tetsuo Maeda, $\mathrm{MD}^{1}$; Takahisa Kamikura, MSc ${ }^{1}$; Taiki Nishi, MSc ${ }^{1}$;

Wataru Omi, MD, $\mathrm{PhD}^{3}$; Masaaki Hashimoto, $\mathrm{MD}, \mathrm{PhD}^{4}$; Satoru Sakagami, $\mathrm{MD}, \mathrm{PhD}^{3}$;

Hideo Inaba, $\mathrm{MD}, \mathrm{PhD}^{1}$

${ }^{1}$ Department of Emergency Medical Science, Kanazawa University Graduate School of Medicine,

13-1 Takara-machi, Kanazawa, Ishikawa 920-8641, Japan; ${ }^{2}$ Department of Surgery, Shin Kyoto-Minami

Hospital, 94 Goshonouchikita-machi, Shimogyo-ku, Kyoto 600-8861, Japan; ${ }^{3}$ Department of Cardiology,

Kanazawa Medical Centre, 1-1 Ishibiki-machi, Kanazawa, Ishikawa 920-8650, Japan; ${ }^{4}$ Emergency

Medical Centre, Noto General Hospital, a-6-4 Fujihashi-machi, Nanao,

Ishikawa 926-0816, Japan 


\section{Address for Correspondence:}

Hideo Inaba, MD, PhD, Professor and Chair

Department of Emergency Medical Science,

Kanazawa University Graduate School of Medicine

13-1 Takara-machi, Kanazawa, Ishikawa 920-8641, Japan

Phone: $+81-76-265-2825$

Fax: $+81-76-234-4243$

E-mail: hidinaba@med.kanazawa-u.ac.jp

Word count: 2996 


\section{Abstract}

Aims - To investigate whether the bystander-patient relationship affects bystander response to out-of-hospital cardiac arrest (OHCA) and patient outcomes depending on the time of day.

Methods-This population-based observational study in Japan involving 139,265 bystander-witnessed

OHCAs (90,426 family members, 10,479 friends/colleagues, and 38,360 others) without prehospital physician involvement was conducted from 2005 to 2009. Factors associated with better bystander response [early emergency call and bystander cardiopulmonary resuscitation (BCPR)] and 1-month neurologically favourable survival were assessed.

Results - The rates of dispatcher-assisted CPR during daytime (7:00-18:59) and nighttime (19:00-6:59) were highest in family members $(45.6 \%$ and $46.1 \%$, respectively, for family members; $28.7 \%$ and $29.2 \%$, respectively, for friends/colleagues; and $28.1 \%$ and $25.3 \%$, respectively, for others). However, the BCPR rates were lowest in family members $(35.5 \%$ and $37.8 \%$, respectively, for family members; $43.7 \%$ and $37.8 \%$, respectively, for friends/colleagues; and 59.3\% and 50.0\%, respectively, for others). Large delays ( $\geq 5 \mathrm{~min}$ ) in placing emergency calls and initiating BCPR were most frequent in family members. The overall survival rate was lowest (2.7\%) for family members and highest $(9.1 \%)$ for friends/colleagues during daytime. Logistic regression analysis revealed that the effect of bystander relationship on survival 
was significant only during daytime [adjusted odds ratios $(95 \% \mathrm{CI})$ for survival from daytime OHCAs

with family as reference were $1.51(1.36-1.68)$ for friends/colleagues and 1.23 (1.13-1.34) for others].

Conclusions -Family members are least likely to perform BCPR and OHCAs witnessed by family

members are least likely to survive during daytime. Different strategies are required for family-witnessed

OHCAs.

Keywords: cardiopulmonary resuscitation; out-of-hospital cardiac arrest; patient survival;

bystander-patient relationship; time of day 


\section{Introduction}

Sudden out-of-hospital cardiac arrest (OHCA) is a significant public health problem. To maximize the chance of favourable outcome, the "chain of survival" concept has emphasized that time-sensitive interventions must be administered to OHCA patients [1].

Most OHCAs are witnessed or discovered by family members at home [2, 3]. Although previous questionnaire surveys showed that a bystander closely related to an OHCA patient is more willing to provide bystander cardiopulmonary resuscitation (BCPR) [4, 5], at-home OHCAs were reported to be associated with poorer BCPR rates and lower survival rates compared with OHCAs occurring at other locations $[2,6,7]$.

The survival rates of all [8] and witnessed [9] OHCAs during nighttime have been reported to be low, presumably because of poor medical resources in hospitals. On the other hand, the frequency of OHCAs witnessed by family members and the number of family members witnessing OHCAs are expected to be low during daytime because some family members are out of the house during normal business hours; this is demographically known as the daytime vs. residential population [10]. However, the effects of the time of day on OHCA outcomes have never been investigated after adjusting for alternation of bystander-patient relationships due to the population shift during daytime in any large 
population-based cohort study.

The present study tested our hypothesis that bystander-patient relationship has a significant effect on bystander responses [early activation of emergency medical services (early emergency call) and early provision of BCPR in accordance with the "chain of survival" concept [1]] and patient outcomes and that the effects of the relationship differ between daytime and nightime.

\section{Methods}

\section{Data collection and study design}

We obtained the consent of the Japanese Fire and Disaster Management Agency (FDMA) to analyse the OHCA data prospectively collected between 2005 and 2009. This Utstein-style database of All-Japan registry system that includes data on patient background, arrest witnesses, aetiology, presence and type of BCPR, presence of dispatcher-assisted CPR (DA-CPR) instruction, initial cardiac rhythm, estimated time of collapse (obtained from interviews with bystanders), times of bystander and EMT CPR initiation and EMT arrival, one-month (1-M) survival, and 1-M neurologically favourable survival (cerebral performance category, 1 or 2 [11]). The study group comprising members of the Ishikawa Medical Control Council and their collaborators conducted this study, which was approved by the review board of 
Ishikawa Medical Control Council.

\section{Data selection}

A total of 547,218 OHCA patients were documented. Of 175,912 bystander-witnessed OHCA patients

transported to hospital, any physician involvement in the prehospital setting was recorded in 30,619 and

unknown in 86 . We first excluded these cases because CPR quality and OHCA outcomes is reported to be

affected by physician involvement $[12,13]$. The bystander-patient relationship was unknown in 160 ,

DA-CPR instruction and/or CPR type (chest compression-only or conventional) were unknown in 2,751,

and other fundamental data for time factors and/or survival were unknown in 3,031. We excluded these

patients from analysis and classified the remaining 139,265 into three groups according to the bystander-

patient relationship: family members, including relatives $(\mathrm{N}=90,426,64.9 \%)$; friends and colleagues,

including workplace colleagues $(\mathrm{N}=10,479,7.5 \%)$; and others, including passers-by, on-duty staff in

public and care facilities, and off-duty nurses and healthcare providers $(\mathrm{N}=38,360,27.5 \%)$ (Figure 1).

According to a preliminary chronological analysis, we defined daytime as 7:00 am to 6:59 pm and

nighttime as 7:00 pm to $6: 59 \mathrm{am}$.

The nationwide Utstein database did not include the data of arrest location or more

comprehensive information on the backgrounds of bystanders. Therefore, in this study, as supplemental 
data to assume the relationship between bystander type and arrest location, we analysed a more extensive

Utstein-style database that was prospectively collected for 8,386 OHCAs that occurred from January 2005

to December 2009 in the Ishikawa Prefecture (Supplementary Table 1). Of the 139,265 witnessed OHCAs

extracted from the nationwide database, 1,200 occurred in Ishikawa Prefecture. Of these, complete case

matching to the nation-wide database was obtained in 1,125 patients, who were divided into three

bystander groups [family members 702 (62.4\%), friends and colleagues $96(8.5 \%)$, and others 327

$(29.1 \%)]$

\section{Population and setting}

Japan has a population of 128 million. In 2009 , the aged population ( $\geq 65$ years) was 28.18 million,

constituting $22.7 \%$ of the total population. The percentage of elderly individuals in the population is the

highest in the world [10].

In 2009, Japan had 803 fire departments with approximately 4,900 ambulance teams [14].

Emergency medical technicians (EMTs) are not allowed to terminate resuscitation on the field unless an

OHCA patient shows rigor mortis, hypostasis, and cloudiness of the cornea or other postmortem changes.

Only authorized and specially trained EMTs are permitted to insert tracheal tubes and administer

intravenous epinephrine. 


\section{Statistical analysis}

We analysed bystander responses and outcomes among the three bystander groups in daytime and

nighttime OHCA subgroups. Differences across groups for nominal variables were assessed with $\chi^{2}$ test

with Pearson's correction and those for continuous variables with the Kruskal-Wallis test. We calculated

both unadjusted and adjusted odds ratio (OR) and 95\% confidence intervals (CIs) for significant variables.

Unadjusted odds ratio was calculated with simple nominal multiple logistic regression analysis. We used

multiple logistic regression analysis to examine the association between bystander-patient relationship

and BCPR provision or 1-M neurologically favourable survival. When building the model for BCPR

provision, we sequentially introduced groups of variables into the model, first DA-CPR and patient age

that were well known to be potentially associated with the presence of BCPR [15-17] and then other

factors in a stepwise manner to obtain the lowest Bayesian information criterion (BIC). When building the

model for 1-M neurologically favourable survival, we sequentially added groups of variables, first

aetiology of arrest, initial rhythm, and interval between call and EMT arrival at patients (response time)

that were well known to be potentially associated with the survival $[11,18]$, and then other factors that

were significant in univariable analysis to obtain the lowest BIC. Generalized $\mathrm{R}^{2}$ was computed as a

measure of fit of the final regression model. We analysed all data using JMP ver. 10 (SAS Institute, Cary, 
NC). For each analysis, the null hypothesis was evaluated at a 2 -sided significant level of $p<0.05$, with

95\% CIs calculated using profile likelihood.

\section{Results}

\section{Differences in OHCA patient and bystander background among the three groups}

As shown in Table 1, OHCA patients witnessed by the friends/colleagues group were youngest among the three bystander groups, whereas those witnessed by the other group were most frequently female. The aetiology of cardiac arrest was most frequently presumed to be cardiac for the friends/colleagues group.

Among the three groups, family members witnessed OHCAs least frequently during daytime.

Supplementary Table 1 shows that family members mostly witnessed OHCAs at home $(92.3 \%$;

648/702). The locations of 96 OHCAs witnessed by friends and colleagues included public places

$(42.7 \% ; 41 / 96)$ and workplaces $(36.5 \% ; 35 / 96)$. Others mostly witnessed OHCAs at care facilities

$(55.0 \% ; 180 / 327)$. The number of rescuers was most frequently one $(64.2 ; 433 / 674)$ and they were most

frequently females $(67.3 \% ; 454 / 675)$ in the family group. Family member bystanders were most

frequently aged $\geq 65$ years $(35.6 \% ; 223 / 626)$. When analysed for OHCAs witnessed by family members at

home, the majority of bystanders were wives and daughters (64.2\%; 451/702), including daughters-in-law 
and granddaughters.

\section{Differences in bystander response among the three groups}

Although DA-CPR instruction was most frequently attempted in family-witnessed OHCAs, it most

frequently resulted in failure to induce BCPR both during daytime and nighttime (Table 2). The rate of

bystander incompliance with DA-CPR (DA-CPR failure to induce BCPR) for family members

moderately decreased during nighttime, while that for friends and colleagues increased. The BCPR rate

was the highest for others and lowest for family members during daytime (unadjusted OR the presence of

BCPR, 95\% CI with family members as reference, $[1.41,1.35-1.48]$ vs. friends/colleagues; $[2.65,2.57-$

2.73 ] vs. others). The BCPR rate among family members slightly increased during nighttime, while those

for the other two groups moderately decreased. The rate of BCPR on bystander's own initiative was

extremely low and was the lowest for family members both during daytime and nighttime.

We compared the interval between witness and emergency call as an early emergency call

index among bystander groups. As shown in Table 2, the median intervals appeared to be same both

during daytime and nighttime. However, the proportion of prolonged delay in placing an emergency call,

defined as a time interval of $\geq 5 \min$ ( $75 \%$ value for all OHCAs), was the highest for family members and

lowest for friends/colleagues both during daytime and nighttime. Next, we compared the interval between 
witness and BCPR initiation as an early CPR index among groups. The interval was longest for family

members and shortest for others both during daytime and nighttime. The proportion of a prolonged delay

in BCPR, defined similarly to the emergency call, was the highest for family members. Overall, the

effects of time of day were absent or negligible.

We used multiple logistic regressions to confirm the association between bystander-patient

relationship and BCPR administration. As shown in Figure 2, with family members as the reference group

$(\mathrm{OR}, 1)$, adjusted ORs, $95 \%$ CIs for BCPR provision during daytime were $(2.45,2.31-2.58)$ for friends

and colleagues and $(4.53,4.38-4.70)$ for others, while those during nighttime were $(1.66,1.51-1.83)$ and

(3.22, 3.06-3.39), respectively. Judging from these adjusted ORs, the effects of bystander-patient

relationship on BCPR administration were prominent during daytime.

\section{Association between bystander-patient relationship and 1-M neurologically favourable survival}

Figure 3 shows that 1-M neurologically favourable survival rate for daytime OHCAs clearly

differed among the three bystander groups; the rate during daytime was consistently the lowest for family

members and highest for friends and colleagues, even when the analysis was performed for two OHCA

subgroups yielding a high survival rate. The 1-M neurologically favourable survival rate for nighttime

OHCAs was significantly lower than that for daytime OHCAs in the two bystander groups other than 
family members. The rate for OHCAs of presumed cardiac aetiology and having BCPR and shockable initial rhythm was the lowest for family members both during daytime and nighttime.

We confirmed the association of bystander-patient relationship with 1-M neurologically favourable survival using multiple logistic regression analysis (Figure 4). During daytime, a family member bystander was significantly associated with 1-M neurologically unfavourable survival (entropy $\left.\mathrm{R}^{2}, 0.234\right)$. With family members as the reference group (OR, 1), the adjusted $\mathrm{OR}, 95 \% \mathrm{CI}$ for favourable survival was $(1.51,1.36-1.68)$ for friends and colleagues and $(1.23,1.13-1.34)$ for others. However, the analysis for nighttime OHCAs disclosed that bystander-patient relationship was not significantly associated with 1-M neurologically favourable survival (entropy $\mathrm{R}^{2}, 0.228$ ).

\section{Discussion}

This study clearly showed that family members are unlikely to perform CPR, particularly during daytime, when they witness an OHCA and that the time for making an emergency call and initiating CPR by family members is frequently delayed. Furthermore, OHCA patients witnessed by family members during daytime are 1.87 to 3.94 times less likely to survive than those witnessed by friends and colleagues and 1.38 to 1.51 times less likely to survive than those witnessed by others. The multiple logistic regression 
analysis confirmed that OHCA patients witnessed by family members during daytime are most unlikely

to exhibit a 1-M neurologically favourable survival. Coincident with the recent reports $[8,9]$, the 1-M

neurologically favourable survival rates of OHCAs witnessed by friends/colleagues and others

considerably decreased during nighttime. However, in this study, neither BCPR nor survival rates of

OHCAs witnessed by family members decreased during nighttime, whereas those witnessed by the other

2 bystander groups decreased during nighttime. These results suggest that the poor outcome of OHCAs

during nighttime is attributable not only to poor medical resources in hospitals, including the reduced

number and/or performance of medical staff, but also to poor bystander response to OHCAs witnessed by

non-family bystanders.

Japan has a rapidly aging population. The number of households with elderly residents is

increasing (42.6\% in 2010) [10]. Males have a shorter lifespan than females. Commonly, a patriarch (or

husband) at retirement age is the one with the first at-home family member-witnessed OHCA, as

demonstrated in this study and others $[19,20]$. According to the Japanese national census [10], males are

more likely to be employed or attending school than females $(91.7 \%$ vs. $73.5 \%)$ in the working

population (15-59 years). Furthermore, in residential areas, because approximately $60 \%$ of the population

is out of the home during business and school hours, the daytime population becomes less than the 
nighttime population [10]. These data and the results of analysis for supplementary data in Ishikawa Prefecture (Supplementary Table 1) indicate that older family members, mostly aged couples are left at home during daytime. Because placing an emergency call is frequently delayed [19] and multiple rescuers are rarely present [21] at home, this environment may be more isolated from the emergency medical service system during daytime. Large questionnaire surveys have shown that elderly citizens are more reluctant to attend BLS courses [22] and perform BLS [23]. Skill retention may be lower in the elderly population [24]. We previously showed that females are less willing to perform BLS, including CPR [23]. Therefore, the situation may not be ameliorated even when a daughter or granddaughter is a witness.

In addition to the above issues that may be specific to Japan and other countries that have an increasingly aging population, it is possible that preparedness for a serious medical emergency at home may be universally poor. Sudden cardiac arrest of a family member may be the last issue for family members to discuss. They may also suffer emotional stress, particularly when they witness a sudden cardiac arrest in one of their family members during daytime as the sole bystander or rescuer. The ability of family bystanders to detect collapse and assess cardiac function is also likely to be extremely low [19]. Cognitive bias may interfere with appropriate recognition of cardiac arrest. For example, family members may take longer to detect cardiac arrest in family patients, because such patients usually lie down at home 
and consequently may be considered resting. This poor ability of family members to detect cardiac arrest may be an important factor affecting the low BCPR rates during daytime. Accordingly, the original protocol for DA-CPR in our community stated that a dispatcher should request a caller to call back using a mobile or wireless phone when they are not in the vicinity of an OHCA patient [16]. It has been reported that chain of survival actions including automated external defibrillator (AED) application were not initiated in all cases of witnessed cardiac arrest even when family members or relatives were trained to take appropriate action [25]. Furthermore, because some family members are aware of the patient's serious health situations and/or implicit end-of-life preferences, these family members may hesitate to perform BCPR.

Consequently, a new strategy is necessary to improve the "chain of survival" actions for family member-witnessed OHCAs during daytime. We should recognize that a near friend with less stress may be better than a near-dwelling family member. If elderly citizens more proactively participate in social events and programs during daytime, the chance of unstressed and well-trained bystanders to witness OHCAs may increase and the rate of survival from OHCAs during daytime may be further improved. The BCPR provision improves the outcome of OHCAs [26] and DA-CPR instruction increases the BCPR rate [16]. Therefore, routine proactive provision of DA-CPR instruction should be combined with a public 
information campaign to facilitate an early emergency call. Previous BLS training courses designed for

public situations where help from others is available need to be revised for small households. In this regard, we have requested a revision for all the fire departments in our community so that it includes realistic simulations of DA-CPR instruction in their training courses for family members who stay at home. The lowest survival rate of OHCAs witnessed by family members during daytime is due, at least in part, to the absence of well-trained bystanders at the scene. Thus, implementation of a community first-responder system [27], engagement of all residents in a small community comprising elderly households in chain of survival initiatives [28], and recruitment of well-trained neighbours and healthcare providers to perform BLS on at-home OHCA patients may be necessary [29].

Our study has several limitations. The bystander classification may be inaccurate when multiple bystanders with different relationships with the patients are present. No data on BCPR quality, known to be a major factor in achieving better OHCA outcomes [30], was collected. Although EMTs were encouraged to identify the time factor by interviewing the bystander(s), the time factor calculated from the estimated time of collapse and CPR initiation may be inaccurate. The relationship between bystander type and arrest location was analysed only in the Ishikawa Prefecture. Because the sample size of the data was too small to reach a definite conclusion, further investigations using a nationwide database 
will be needed to elucidate the effects of the bystander-patient relationship and locations on patient

response and survival. However, this study contains a notably large prospective cohort, and the results will be useful for designing new strategies to deal with family member-witnessed OHCAs.

\section{Conclusions}

Despite current educational efforts, our findings suggest that it is unlikely that a family member who witnesses an OHCA in Japan will respond appropriately, particularly during daytime. Although previous questionnaire surveys indicated that family members would be the most willing to initiate $\mathrm{BCPR}$ and respond to DA-CPR instructions, they are actually the ones who least frequently perform desirable actions when they witness a family member suffering an OHCA. Furthermore, a family member bystander is associated with 1-M neurologically unfavourable survival in daytime OHCA patients. Therefore, different strategies should be designed to deal with family member-witnessed OHCA patients, particularly during daytime.

\section{Acknowledgements}

We would like to thank all of the EMS personnel and the FDMA in Japan for their great cooperation in 
collecting and managing the Utstein-style database.

\section{Conflict of interest statement}

None.

\section{References}

1. Nolan JP, Soar J, Zideman DA, et al.; ERC Guidelines Writing Group. European Resuscitation Council

Guidelines for Resuscitation 2010 Section 1. Executive summary. Resuscitation. 2010;81:1219-1276.

2. Swor RA, Jackson RE, Compton S, et al. Cardiac arrest in private locations: different strategies are needed to improve outcome. Resuscitation. 2003;58:171-176.

3. Eisenberg MS, Mengert TJ. Cardiac resuscitation. N Engl J Med. 2001;344:1304-1313.

4. Axelsson A, Thoren A, Holmberg S, Herlitz J. Attitudes of trained Swedish lay rescuers toward CPR performance in an emergency. A survey of 1012 recently trained CPR rescuers. Resuscitation.

2000;44:27-36.

5. Jelinek GA, Gennat H, Celenza T, O'Brien D, Jacobs I, Lynch D. Community attitudes towards

performing cardiopulmonary resuscitation in Western Australia. Resuscitation. 2001;51:239-246. 
6. Herlitz J, Eek M, Holmberg M, Engdahl J, Holmberg S. Characteristics and outcome among patients having out of hospital cardiac arrest at home compared with elsewhere. Heart. 2002;88:579-582.

7. Weisfeldt ML, Everson-Stewart S, Sitlani C, et al.; Resuscitation Outcomes Consortium Investigators. Ventricular tachyarrhythmias after cardiac arrest in public versus at home.

N Engl J Med. 2011;364:313-321.

8. Wallace SK, Abella BS, Shofer FS, et al. Effect of time of day on prehospital care and outcomes after out-of-hospital cardiac arrest. Circulation. 2013;27:1591-1596.

9. Koike S, Tanabe S, Ogawa T, et al. Effect of time and day of admission on 1-month survival and neurologically favourable 1-month survival in out-of-hospital cardiopulmonary arrest patients.

Resuscitation. 2011; 82: 863-868.

10. Ministry of internal affairs and communications Statics bureau, Director-general for policy planning (statistical standards) \& statistical research and training institute. (Accessed 2, September 2014, http://www.stat.go.jp/english/index.htm).

11. Jacobs I, Nadkarni V, Bahr J, et al. Cardiac arrest and cardiopulmonary resuscitation outcome reports: update and simplification of the Utstein templates for resuscitation registries: a statement for healthcare professionals from a task force of the International Liaison Committee on Resuscitation (American Heart 
Association, European Resuscitation Council, Australian Resuscitation Council, New Zealand

Resuscitation Council, Heart and Stroke Foundation of Canada, Inter American Heart Foundation,

Resuscitation Councils of Southern Africa). Circulation. 2004;23:3385-3397.

12. Yasunaga $\mathrm{H}$, Horiguchi $\mathrm{H}$, Tanabe $\mathrm{S}$, et al.

Collaborative effects of bystander-initiated cardiopulmonary resuscitation and prehospital

advanced cardiac life support by physicians on survival of out-of-hospital cardiac arrest:

a nationwide population-based observational study. Crit Care. 2010; 14: R199.

13. Hagihara A, Hasegawa M, Abe T, Nagata T, Nabeshima Y. Physician presence in an

ambulance car is associated with increased survival in out-of-hospital cardiac arrest: a

prospective cohort analysis. PLoS One. 2014; 9: e84424.

14. Fire and Disaster Management Agency. (Accessed 2, September 2014, at http://www.fdma.go.jp/en/).

15. Bohm K, Vaillancourt C, Charette ML, Dunford J, Castrén M. In patients with out-of cardiac arrest, dose the provision of dispatch cardiopulmonary resuscitation instruction as opposed to no instructions

improve outcome: a systematic review of the literature. Resuscitation. 2011; 82: 1490-1495.

16. Tanaka Y, Taniguchi J, Wato Y, Yoshida Y, Inaba H. The continuous quality improvement project for telephone-assisted instruction of cardiopulmonary resuscitation increased the incidence of bystander CPR 
and improved the outcomes of out-of-hospital cardiac arrests. Resuscitation. 2012;83:1235-1241.

17. Tanaka Y, Nishi T, Takase K, et al. Survey of a protocol to increase appropriate implementation of dispatcher-assisted cardiopulmonary resuscitation for out-of-hospital cardiac arrest. Circulation. 2014;

129: $1751-1760$.

18. Pell JP, Sirel JM, Marsden AK, Ford I, Cobbe SM. Effect of reducing ambulance response times on deaths from out of hospital cardiac arrest: cohort study. BMJ. 2001; 322: 1385-1388.

19. Breckwoldt J, Schloesser S, Arntz HR. Perceptions of collapse and assessment of cardiac arrest by bystanders of out-of-hospital cardiac arrest (OOHCA). Resuscitation. 2009;80:1108-1113.

20. Engdahl J, Holmberg M, Karlson BW, Luepker R, Herlitz J. The epidemiology of out-of-hospital ‘sudden’ cardiac arrest. Resuscitation. 2002; 52: 235-245.

21. Nishi T, Maeda T, Takase K, Kamikura T, Tanaka Y, Inaba H. Does the number of rescuers affect the survival rate from out-of-hospital cardiac arrests? Two or more rescuers are not always better than one.

Resuscitation. 2013;84:154-161.

22. Keim SM, Anderson K, Siegel E, Spaite DW, Valenzuela TD. Factors associated with CPR certification within an elderly community. Resuscitation. 2001;51:269-274.

23. Enami M, Takei $Y$, Inaba $H$, et al. Differential effects of ageing and previous training experience on 
attitude towards basic life support. Resuscitation. 2011;82:577-583.

24. Swor R, Compton S, Vining F, et al. A randomized controlled trial of chest compression only CPR for older adults-a pilot study. Resuscitation. 2003;58:177-185.

25. Bardy GH, Lee KL, Mark DB, et al.; HAT Investigators. Home use of automated external defibrillators for sudden cardiac arrest. N Engl J Med. 2008;358:1793-1804.

26. Stiell IG, Wells GA, Field B, et al.; Ontario Prehospital Advanced Life Support Study Group. Advanced cardiac life support in out-of-hospital cardiac arrest.

N Engl J Med. 2004;351:647-656.

27. Rørtveit S, Meland M. First responder resuscitation teams in a rural Norwegian community: sustainability and self-reports of meaningfulness, stress and mastering. Scand J Trauma Resusc Emerg Med. 2010;18:25.

28. Møller Nielsen A, Lou Isbye D, Knudsen Lippert F, Rasmussen LS. Engaging a whole community in resuscitation. Resuscitation. 2012;83:1067-1071.

29. AHA Scientific Statements/Guidelines. Targeting CPR education in high-risk neighborhoods could save more lives. (Accessed 2, September 2014, http://newsroom.heart.org/news/targeting-cpr-education-in-high-risk-neighborhoods-could-save-more-liv 
es).

30. Gallagher EJ, Lombardi G, Gennis P. Effectiveness of bystander cardiopulmonary resuscitation and survival following out-of-hospital cardiac arrest. JAMA. 1995;274:1922-1925.

\section{Figure legends}

Figure 1. Overview of nationwide data collection and selection

Figure 2. Factors associated with bystander cardiopulmonary resuscitation

DA-CPR, dispatcher-assisted cardiopulmonary resuscitation; BCPR, bystander cardiopulmonary

resuscitation; OR, odds ratio; 95\% CI, 95\% confidence interval.

Adjusted results using multiple logistic regression analysis are shown.

We used multiple logistic regression modeling to examine the association between BCPR administration and bystander-patient relationship. When building the model for the presence of $\mathrm{BCPR}$, we sequentially introduced groups of variables into the model, first DA-CPR and patient age that were expected to be associated with the presence of BCPR [15-17] and then other basic factors in a stepwise manner to obtain 
the lowest Bayesian information criterion. All factors were included in the final model. Generalized

R-square of the final model was 0.250 and 0.272 for daytime and nighttime OHCAs, respectively.

Figure 3. Comparison of 1-M neurologically favourable survival among the three bystander groups

for daytime and nighttime OHCA patients

OR $(95 \% \mathrm{CI})$ was determined by simple logistic regression analysis.

* Significantly different from the corresponding value of daytime OHCAs. P-values are form $2 \times 2$

Fisher's exact probability test or $\chi^{2}$ test with the Pearson's correction as appropriate.

Figure 4. Factors associated with one-month neurologically favourable survival

BCPR, bystander cardiopulmonary resuscitation; EMT, emergency medical technician; OR, odds ratio;

95\% CI, 95\% confidence interval.

Adjusted results using multiple logistic regression analysis are shown.

We used multiple logistic regression to examine the association between bystander-patient relationship

and 1-M neurologically favourable survival. We sequentially added groups of variables, first aetiology of

arrest, initial rhythm, and interval between call and EMT arrival at patients (response time) that were all 
reported to be potentially associated with the survival $[11,18]$, and then other factors that were significant in univariable analysis to obtain the lowest Bayesian information criterion (BIC). Patient sex and time interval of arrival at patient - arrival at hospital were excluded from the final model because these two factors produced no further improvement of BIC. Generalized R-square of the final model was 0.234 and 0.228 for daytime and nighttime OHCAs, respectively. 
All OHCAs transported to hospital in 2005-2009

$$
N=547,218
$$

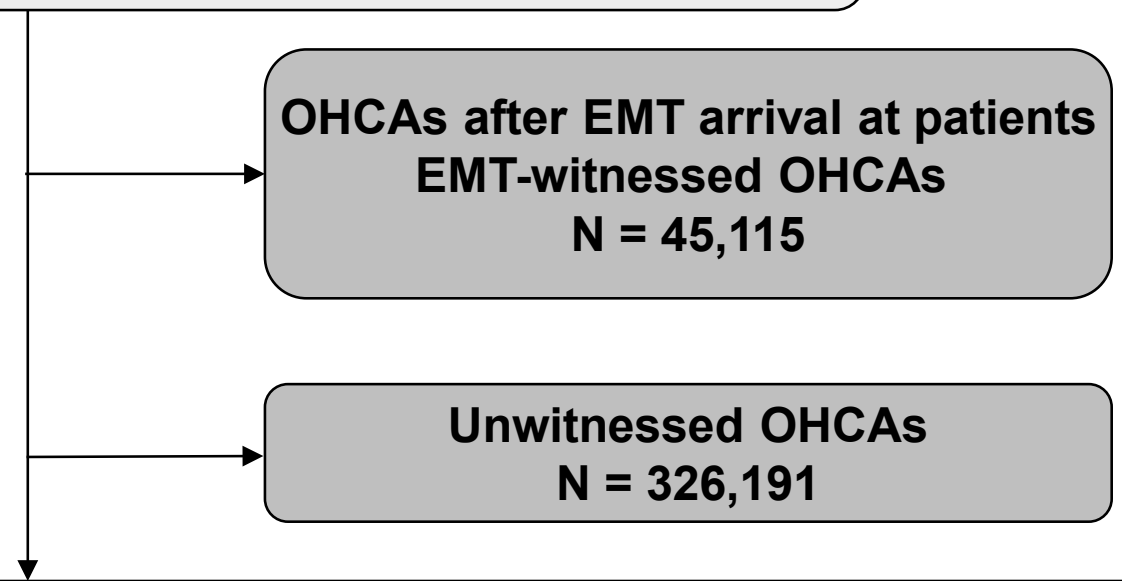

\section{Bystander-witnessed OHCA transported to hospitals}

$\mathrm{N}=175,912$

\begin{tabular}{|c|}
$\begin{array}{c}\text { Involvement of physician } \\
\mathrm{N}=30,619\end{array}$ \\
$\longrightarrow \begin{array}{c}\text { Involvement of physician unknown } \\
\mathrm{N}=86\end{array}$ \\
\hline
\end{tabular}

Bystander-witnessed OHCA transported to hospitals without any prehospital involvement of physician $N=145,207$

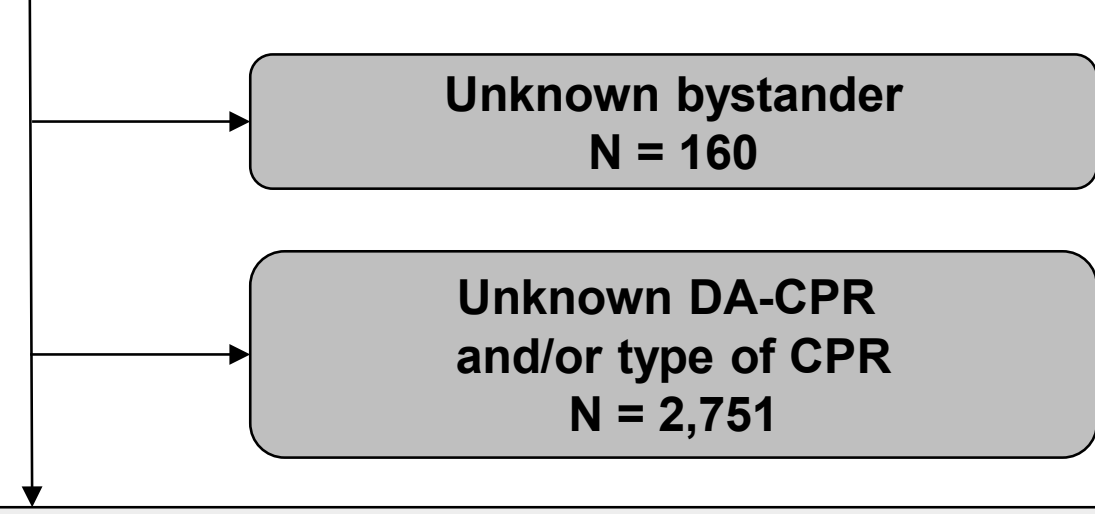

Bystander-witnessed OHCA transported to hospitals without any prehospital involvement of physician, having information about bystander, DA-CPR and type of CPR

$\mathrm{N}=142,296$

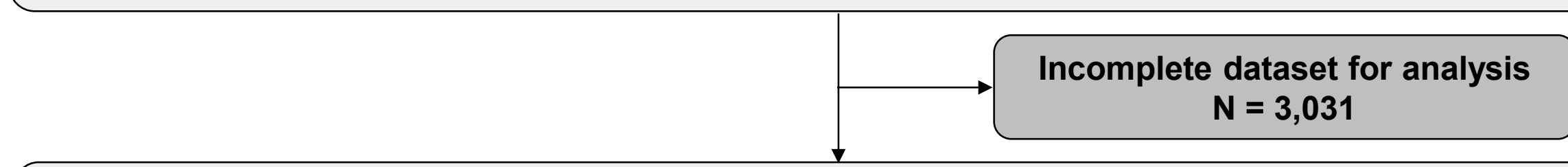

Bystander-witnessed OHCA transported to hospitals without any prehospital involvement of physician, having complete dataset for analysis and information about DA-CPR and type of CPR

$N=139,265$

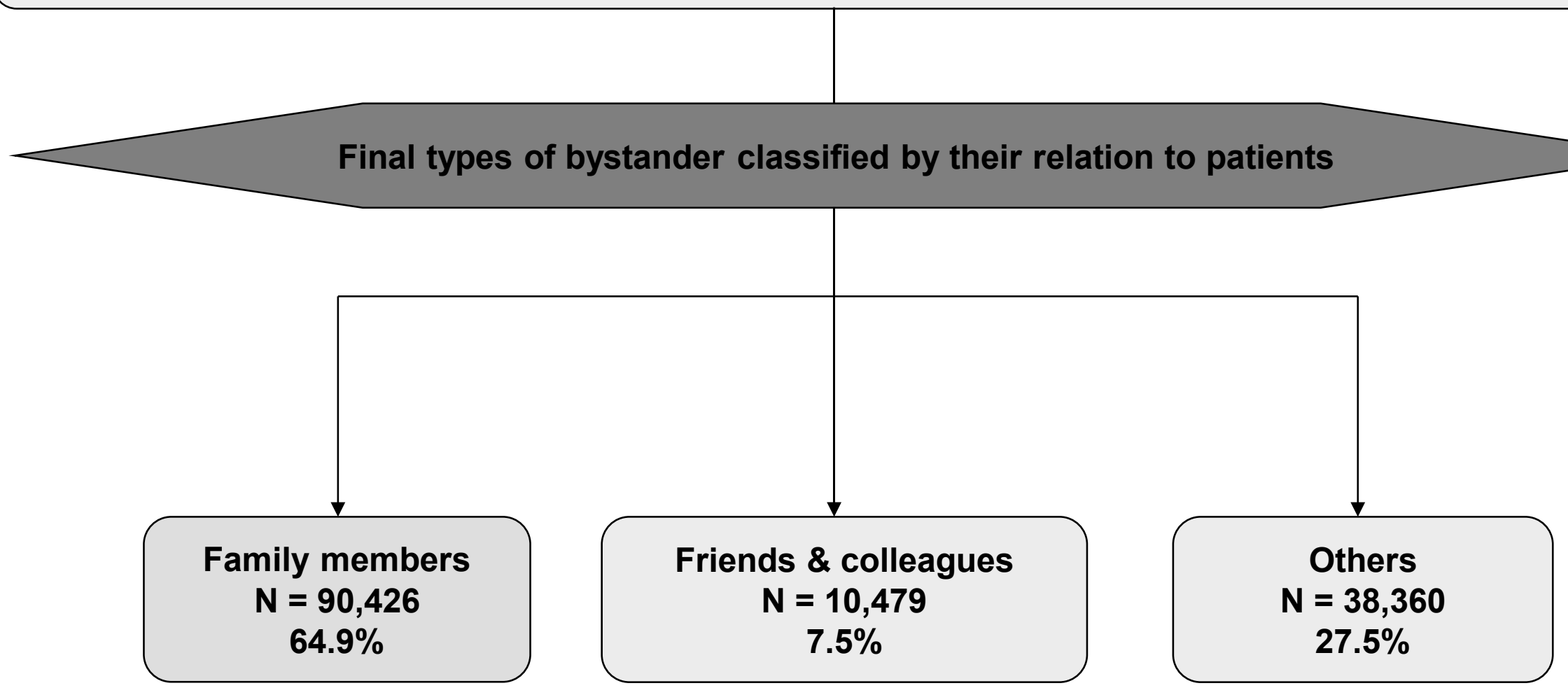




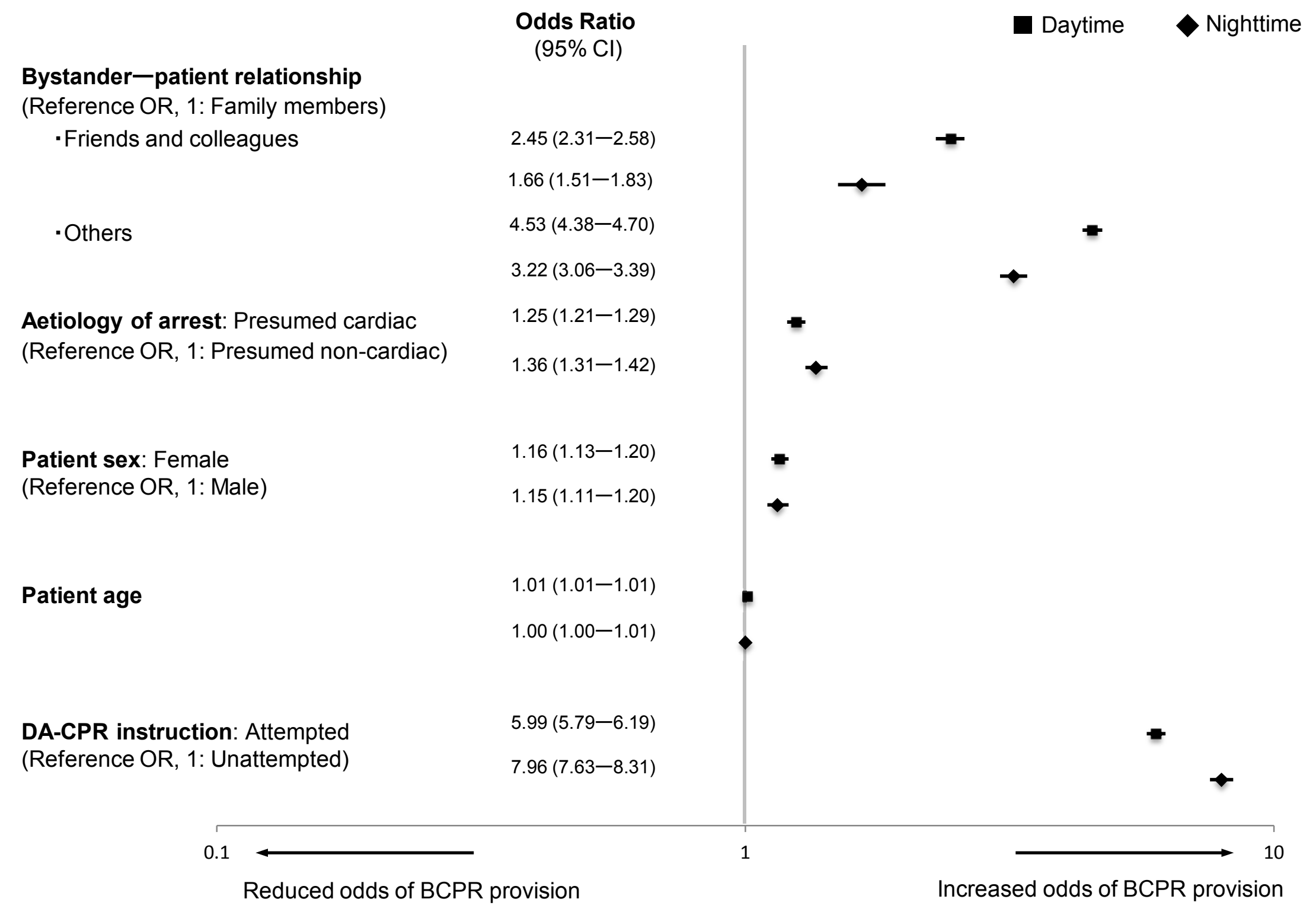


Daytime

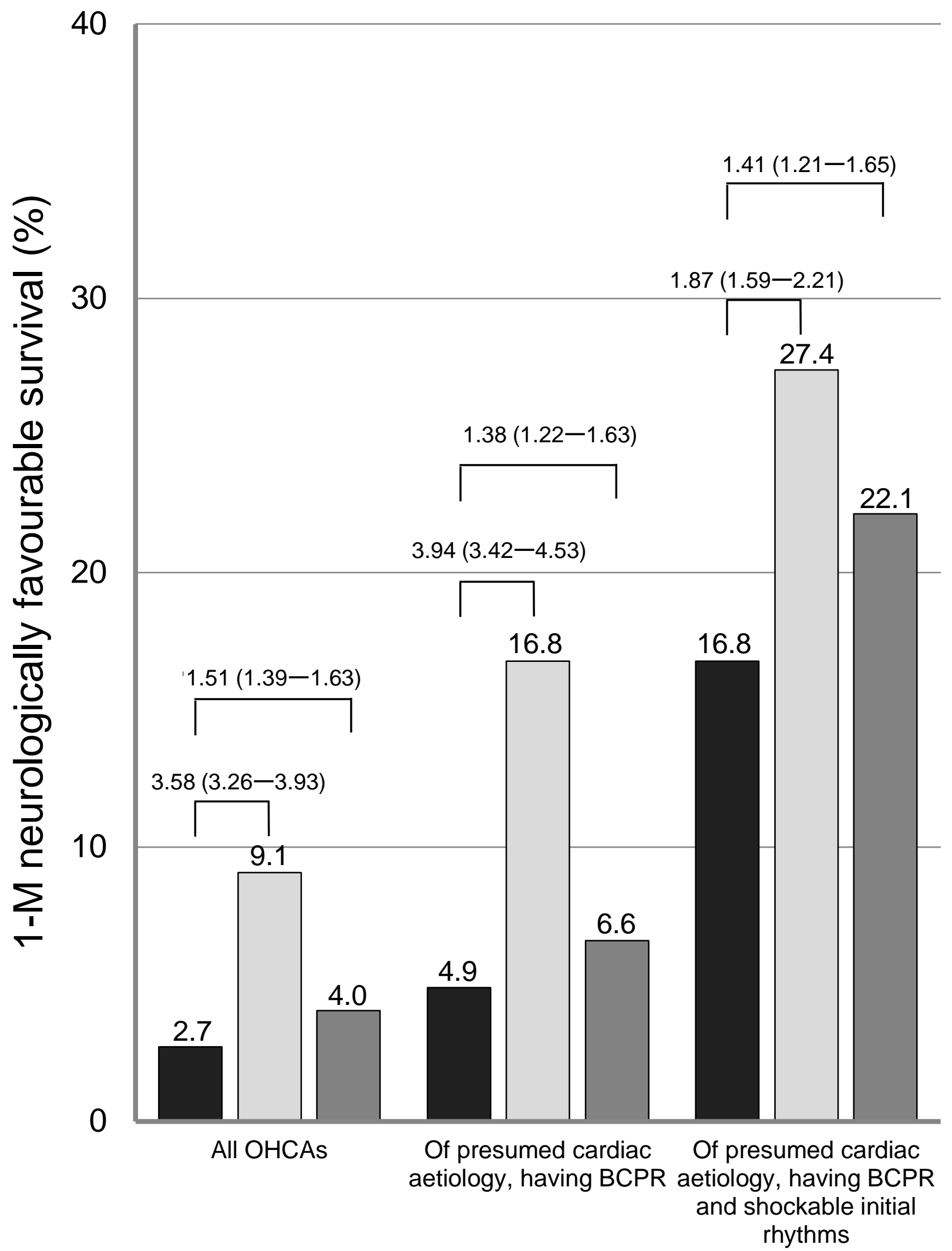

- Family members
Nighttime

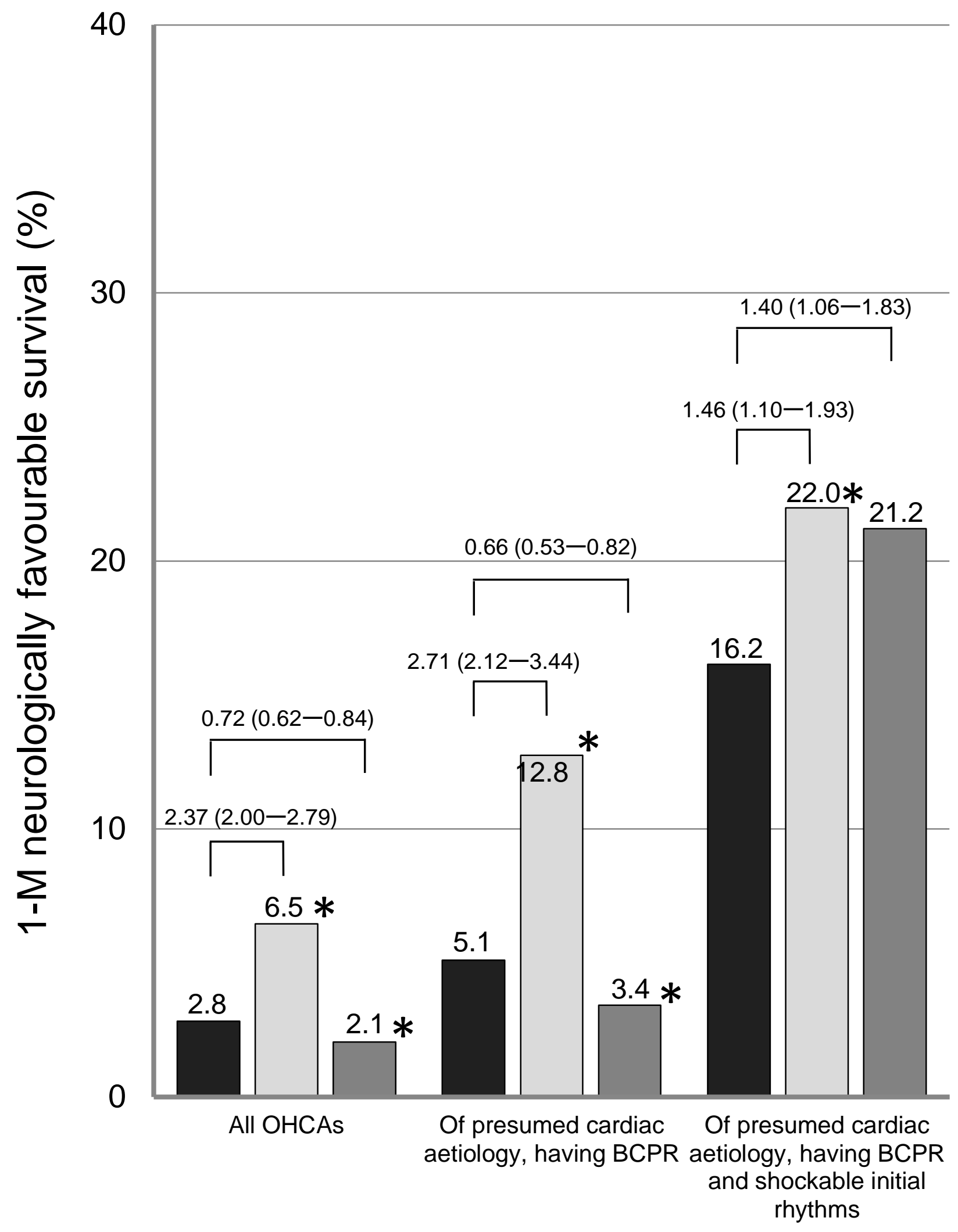

घFamily members $\square$ Friends and colleagues

$\square$ Others 


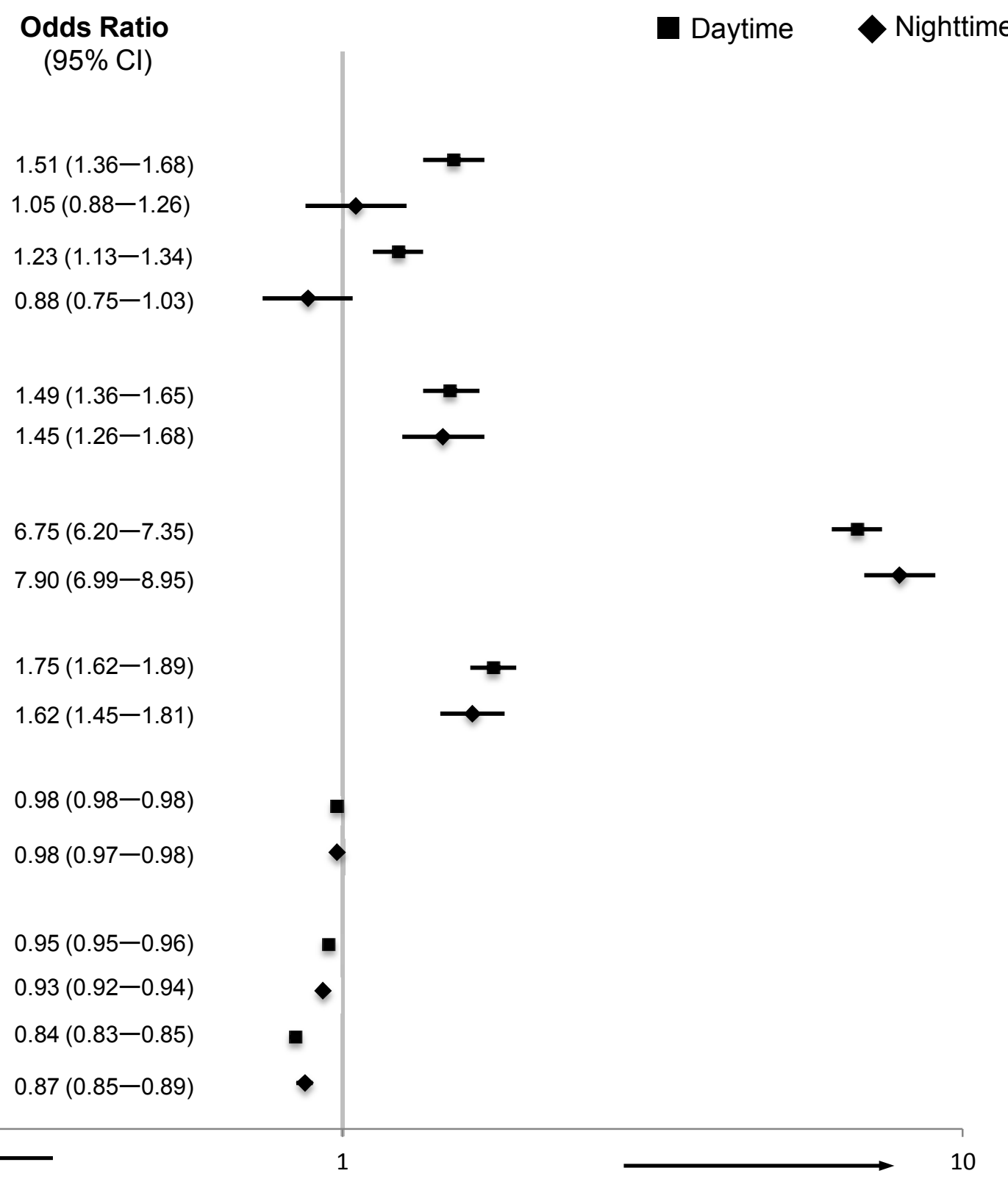

\section{Bystander-patient relationship}

(Reference OR, 1: Family members)

- Friends and colleagues

- Others

Aetiology of arrest: Presumed cardiac (Reference OR, 1: Presumed non-cardiac)

Initial rhythm: Shockable

(Reference OR, 1: Non-shockable)

\section{BCPR: Provision}

(Reference OR, 1: Absent)

\section{Patient age}

\section{Time factors}

-Witness-call

- Call-arrival at patient
Odds Ratio

$(95 \% \mathrm{Cl})$

$$
\begin{aligned}
& 1.51(1.36-1.68) \\
& 1.05(0.88-1.26) \\
& 1.23(1.13-1.34) \\
& 0.88(0.75-1.03)
\end{aligned}
$$

$1.49(1.36-1.65)$

$1.45(1.26-1.68)$

$6.75(6.20-7.35)$

$7.90(6.99-8.95)$

$$
1.75(1.62-1.89)
$$

$1.62(1.45-1.81)$

$0.98(0.98-0.98)$

$0.98(0.97-0.98)$

$0.95(0.95-0.96)$

$0.93(0.92-0.94)$

$0.84(0.83-0.85)$

$0.87(0.85-0.89)$ 
Table 1. Differences in background among the bystander groups classified by the bystander-patient relationship in bystander-witnessed OHCA patients

\begin{tabular}{|c|c|c|c|c|}
\hline \multirow[b]{2}{*}{ Background and characteristics } & \multicolumn{3}{|c|}{ Bystander-patient relationship } & \multirow[b]{2}{*}{$p$ value $^{\dagger}$} \\
\hline & $\begin{array}{l}\text { Family members } \\
\qquad(\mathrm{N}=90,426)\end{array}$ & $\begin{array}{l}\text { Friends and colleagues } \\
\qquad(\mathrm{N}=10,479)\end{array}$ & $\begin{array}{c}\text { Others } \\
(\mathrm{N}=38,360)\end{array}$ & \\
\hline Patient age, median (25-75\%) & $77(67-84)$ & $60(49-71)$ & $79(64-87)$ & $p<0.01$ \\
\hline $\begin{array}{l}\text { Female patient, } \%(\mathrm{~N}) \\
{[\mathrm{OR}, 95 \% \mathrm{CI}]^{*}}\end{array}$ & $\begin{array}{c}37.7 \%(34,151) \\
\text { [Reference] }\end{array}$ & $\begin{array}{c}21.2 \%(2,217) \\
{[0.44,0.42-0.46]}\end{array}$ & $\begin{array}{c}46.9 \%(17,996) \\
{[1.46,1.42-1.49]}\end{array}$ & $p<0.01$ \\
\hline $\begin{array}{l}\text { Presumed cardiac aetiology, } \%(\mathrm{~N}) \\
{[\mathrm{OR}, 95 \% \mathrm{CI}]^{*}}\end{array}$ & $\begin{array}{c}58.2 \%(52,632) \\
{[\text { Reference] }}\end{array}$ & $\begin{array}{c}63.2 \%(6,622) \\
{[1.23,1.18-1.29]}\end{array}$ & $\begin{array}{c}48.1 \%(38,360) \\
{[0.67,0.65-0.68]}\end{array}$ & $p<0.01$ \\
\hline $\begin{array}{l}\text { Shockable initial rhythm, } \%(\mathrm{~N}) \\
{[\mathrm{OR}, 95 \% \mathrm{CI}]^{*}}\end{array}$ & $\begin{array}{c}13.1 \%(11,842) \\
\text { [Reference] }\end{array}$ & $\begin{array}{c}31.4 \%(3,288) \\
{[3.03,2.90-3.18]}\end{array}$ & $\begin{array}{c}11.8 \%(4,513) \\
{[0.89,0.85-0.92]}\end{array}$ & $p<0.01$ \\
\hline $\begin{array}{l}\text { Public access defibrillation, } \%(\mathrm{~N}) \\
{[\mathrm{OR}, 95 \% \mathrm{CI}]^{*}}\end{array}$ & $\begin{array}{l}0.1 \%(126) \\
{[\text { Reference] }}\end{array}$ & $\begin{array}{c}2.6 \%(276) \\
{[19.4,15.73-24.04]}\end{array}$ & $\begin{array}{c}1.7 \%(654) \\
{[12.47,10.34-15.16]}\end{array}$ & $p<0.01$ \\
\hline Hour of OHCA witness, daytime & $56.9 \%(51,446)$ & $74.7 \%(7,830)$ & $73.0 \%(28,013)$ & \\
\hline $\begin{array}{l}(7: 00 \mathrm{am}-6: 59 \mathrm{pm}), \%(\mathrm{~N}) \\
{[\mathrm{OR}, 95 \% \mathrm{CI}]^{*}}\end{array}$ & [Reference] & {$[2.24,2.14-2.35]$} & {$[2.05,2.00-2.11]$} & $p<0.01$ \\
\hline
\end{tabular}

OHCA, out-of-hospital cardiac arrest.

* Odds ratio (OR) and 95\% confidence interval (CI) were determined by simple logistic regression analysis (family member as reference). $\uparrow 3 \times 2 \chi^{2}$ test with the Pearson's correction or the Kruskal-Wallis test as appropriate. 
Table 2. Differences in bystander response incidence among the three bystander groups

\begin{tabular}{|c|c|c|c|c|c|c|c|c|}
\hline & \multicolumn{4}{|c|}{ Daytime } & \multicolumn{4}{|c|}{ Nighttime } \\
\hline & \multicolumn{3}{|c|}{ Bystander-patient relationship } & \multirow[b]{2}{*}{$P$ value $^{\dagger}$} & \multicolumn{3}{|c|}{ Bystander-patient relationship } & \multirow[b]{2}{*}{$P$ value ${ }^{\dagger}$} \\
\hline & $\begin{array}{c}\text { Family } \\
\text { members } \\
(\mathrm{N}=51,446) \\
\end{array}$ & $\begin{array}{l}\text { Friends and } \\
\text { colleagues } \\
(\mathrm{N}=7,830) \\
\end{array}$ & $\begin{array}{c}\text { Others } \\
(\mathrm{N}=28,013)\end{array}$ & & $\begin{array}{c}\text { Family } \\
\text { members } \\
(\mathrm{N}=38,980)\end{array}$ & $\begin{array}{l}\text { Friends and } \\
\text { colleagues } \\
(\mathrm{N}=2,649) \\
\end{array}$ & $\begin{array}{c}\text { Others } \\
(\mathrm{N}=10,347)\end{array}$ & \\
\hline $\begin{array}{l}\text { DA-CPR instruction - } \\
\text { attempted, } \\
\%(\mathrm{~N})[\mathrm{OR}, 95 \% \mathrm{CI}]^{*}\end{array}$ & $\begin{array}{l}45.6 \% \\
(23,458) \\
\text { [Reference] }\end{array}$ & $\begin{array}{l}28.7 \% \\
(2,246) \\
{[0.48,0.46-0.51]}\end{array}$ & $\begin{array}{l}28.1 \% \\
(7,868) \\
{[0.47,0.45-0.48]}\end{array}$ & $p<0.01$ & $\begin{array}{l}46.1 \% \\
(17,984) \\
\text { [Reference] }\end{array}$ & $\begin{array}{l}29.2 \% \\
(774) \\
{[0.48,0.44-0.53]}\end{array}$ & $\begin{array}{l}25.3 \%^{\ddagger} \\
(2,616) \\
{[0.40,0.38-0.42]}\end{array}$ & $p<0.01$ \\
\hline $\begin{array}{l}\text { Failure to induce } \\
\text { BCPR/attempted } \\
\text { cases, } \\
\%(N) \\
{[\mathrm{OR}, 95 \% \mathrm{CI}]^{*}}\end{array}$ & $\begin{array}{l}41.4 \% \\
(9,701) \\
{[\text { Reference] }}\end{array}$ & $\begin{array}{l}27.3 \% \\
(614) \\
{[0.53,0.48-0.59]}\end{array}$ & $\begin{array}{l}20.6 \% \\
(1,624) \\
{[0.37,0.35-0.39]}\end{array}$ & $p<0.01$ & $\begin{array}{l}36.7 \%^{\ddagger} \\
(6,614) \\
\text { [Reference] }\end{array}$ & $\begin{array}{l}34.1 \%^{\ddagger} \\
(264) \\
{[0.89,0.76-1.04]}\end{array}$ & $\begin{array}{l}22.9 \% \\
(600) \\
{[0.51,0.46-0.56]}\end{array}$ & $p<0.01$ \\
\hline $\begin{array}{l}\text { BCPR-present, } \\
\% \text { (N) [OR, 95\% CI] }\end{array}$ & $\begin{array}{l}35.5 \% \\
(18,256) \\
\text { [Reference] }\end{array}$ & $\begin{array}{l}43.7 \% \\
(3,424) \\
{[1.41,1.35-1.48]}\end{array}$ & $\begin{array}{l}59.3 \% \\
(16,613) \\
{[2.65,2.57-2.73]}\end{array}$ & $p<0.01$ & $\begin{array}{l}37.8 \% \%^{\ddagger} \\
(14,752) \\
\text { [Reference] }\end{array}$ & $\begin{array}{l}37.8 \% \\
(1,000) \\
{[0.99,0.92-1.08]}\end{array}$ & $\begin{array}{l}50.0 \% \\
(5,173) \\
{[1.64,1.57-1.72]}\end{array}$ & $p<0.01$ \\
\hline $\begin{array}{l}\text { BCPR on own } \\
\text { initiative, } \\
\%(\mathrm{~N})[\mathrm{OR}, 95 \% \mathrm{CI}]^{*}\end{array}$ & $\begin{array}{l}24.6 \% \\
(4,499) \\
\text { [Reference] }\end{array}$ & $\begin{array}{l}52.3 \% \\
(1,792) \\
{[3.36,3.12-3.62]}\end{array}$ & $\begin{array}{l}62.4 \% \\
(10,369) \\
{[5.08,4.85-5.32]}\end{array}$ & $p<0.01$ & $\begin{array}{l}22.9 \% \%^{*} \\
(3,382) \\
\text { [Reference] }\end{array}$ & $\begin{array}{l}49.0 \% \\
(490) \\
{[3.23,2.84-3.68]}\end{array}$ & $\begin{array}{l}61.0 \% \\
(3,157) \\
{[5.27,4.92-5.64]}\end{array}$ & $p<0.01$ \\
\hline \multicolumn{9}{|c|}{ Largely delayed emergency call } \\
\hline $\begin{array}{l}\text { Witness-call interval, } \\
\text { median } \\
(10-25-75-90 \%)\end{array}$ & $\frac{2}{(-3-0-5-11)}$ & $\begin{array}{l}2 \\
(-3-0-4-9)\end{array}$ & $\begin{array}{l}2 \\
(-4-0-4-9)\end{array}$ & $p<0.01$ & $\frac{2}{(-4-0-5-12)}$ & $\frac{2}{(-3-0-2-10)}$ & $\begin{array}{l}2^{\ddagger} \\
(-4-0-5-11)\end{array}$ & $p<0.01$ \\
\hline $\begin{array}{l}\text { Witness-call } \geq 5 \mathrm{~min}, \\
\%(\mathrm{~N}) \\
{[\mathrm{OR}, 95 \% \mathrm{CI}]^{*}}\end{array}$ & $\begin{array}{l}22.7 \% \\
(11,691) \\
\text { [Reference] }\end{array}$ & $\begin{array}{l}18.5 \% \\
(1,447) \\
{[0.77,0.73-0.82]}\end{array}$ & $\begin{array}{l}18.7 \% \\
(5,230) \\
{[0.78,0.75-0.81]}\end{array}$ & $p<0.01$ & $\begin{array}{l}24.2 \%^{\ddagger} \\
(9,412) \\
\text { [Reference] }\end{array}$ & $\begin{array}{l}20.1 \% \\
(532) \\
{[0.79,0.72-0.87]}\end{array}$ & $\begin{array}{l}22.9 \% \\
(2,365) \\
{[0.93,0.88-0.98]}\end{array}$ & $p<0.01$ \\
\hline
\end{tabular}

\section{Largely delayed BCPR ${ }^{\S}$}


Witness-BCPR

interval, median

(10-25-75-90\%)

Witness-BCPR $\geq 5$

$\min , \%(\mathrm{~N})$

[OR, 95\% CI]
3

(0-1-6-11)

2

$26.0 \%$

$(4,592)$

[Reference]
$17.8 \% \quad 9.3 \%$

$(587) \quad(1,514)$

$[0.62,0.57-0.69]$
1

$p<0.01$

3

$(0-0-5-9)$

$(0-0-2-6)$

$p<0.01$

$[0.29,0.28-0.31]$ $p<0.01$

$26.8 \%$

$(3,845)$

[Reference]
$18.2 \%(176)$

$11.1 \%(557)$

$p<0.01$
$[0.62,0.53-0.73]$

$[0.35,0.31-0.38$

DA-CPR, dispatcher-assisted cardiopulmonary resuscitation; BCPR, bystander cardiopulmonary resuscitation; emergency call, emergency response number call

* Odds ratio (OR) and 95\% confidence interval (CI) were determined by simple logistic regression analysis (family member as reference).

$\dagger 3 \times 2 \chi^{2}$ test with the Pearson's correction or the Kruskal-Wallis test as appropriate.

+ Significantly different from the corresponding daytime value.

$\S$ Determined only in cases that received BCPR. 
Supplementary Table 1. Relationship between bystander group and arrest location or bystander background in Ishikawa Prefecture

\begin{tabular}{|c|c|c|c|c|}
\hline \multirow[b]{2}{*}{ Background and characteristics } & \multicolumn{3}{|c|}{ Bystander-patient relationship } & \multirow[b]{2}{*}{$p$ value $^{\dagger}$} \\
\hline & $\begin{array}{l}\text { Family members } \\
(\mathrm{N}=702)\end{array}$ & $\begin{array}{l}\text { Friends and } \\
\text { colleagues } \\
(\mathrm{N}=96)\end{array}$ & $\begin{array}{l}\text { Others } \\
(\mathrm{N}=327)\end{array}$ & \\
\hline Patient age, median $(25-75 \%)$ & $77(66-84)$ & $59(51-66)$ & $82(71-89)$ & $p<0.01$ \\
\hline Female patient, $\%(\mathrm{~N})$ & $31.1 \%(218)$ & $14.6 \%(14)$ & $51.4 \%(168)$ & $p<0.01$ \\
\hline Presumed cardiac aetiology, \% (N) & $51.1 \%(359)$ & $56.3 \%(54)$ & $57.8 \%(189)$ & $p<0.01$ \\
\hline Public access defibrillation, $\%(\mathrm{~N})$ & $0 \%(0)$ & $1.0 \%(1)$ & $2.4 \%(8)$ & undefined \\
\hline Shockable initial rhythm, \% (N) & $17.2 \%(121)$ & $37.5 \%(36)$ & $8.6 \%(28)$ & $p<0.01$ \\
\hline $\begin{array}{l}\text { Daytime (7:00 am-6:59 pm) OHCA, \% } \\
(\mathrm{N})\end{array}$ & $56.4 \%(396)$ & $69.8 \%(67)$ & $74.0 \%(242)$ & $p<0.01$ \\
\hline DA-CPR provision, $\%(\mathrm{~N})$ & $59.1 \%(415)$ & $46.9 \%(45)$ & $36.1 \%(118)$ & $p<0.01$ \\
\hline BCPR provision, $\%(\mathrm{~N})$ & $45.2 \%(317)$ & $49.0 \%(47)$ & $68.2 \%(223)$ & $p<0.01$ \\
\hline Location, $\%(\mathrm{~N})$ & & & & undefined \\
\hline Home & $92.3 \%(648)$ & $9.4 \%(9)$ & $11.9 \%(39)$ & \\
\hline Care facilities & $0.6 \%$ & $2.1 \%(2)$ & $55.0 \%(180)$ & \\
\hline Public places & $3.4 \%(27)$ & $42.7 \%(41)$ & $16.5 \%(54)$ & \\
\hline Streets & $2.0 \%(14)$ & $4.2 \%(4)$ & $13.1 \%(43)$ & \\
\hline Workplaces & $0.7 \%(5)$ & $36.5 \%(35)$ & $0.3 \%(1)$ & \\
\hline Other locations & $0.6 \%$ & $5.2 \%(5)$ & $3.1 \%(10)$ & \\
\hline Single rescuer*, \% (N) & $64.2 \%(433 / 674)$ & $28.0 \%(26 / 93)$ & $38.3 \%(119 / 311)$ & $p<0.01$ \\
\hline Female bystander*, \% (N) & $67.3 \%(454 / 675)$ & $18.8 \%(18 / 96)$ & $66.7 \%(214 / 321)$ & $p<0.01$ \\
\hline Elderly ( $\geq 65$ years) bystander*, $\%(\mathrm{~N})$ & $35.6 \%(223 / 626)$ & $16.0 \%(15 / 94)$ & $3.2 \%(10 / 315)$ & $p<0.01$ \\
\hline
\end{tabular}

OHCA, out-of-hospital cardiac arrest; DA-CPR, dispatcher-assisted cardiopulmonary resuscitation; BCPR, bystander cardiopulmonary resuscitation

* Undefined in some cases.

$\dagger 3 \times 2 \chi^{2}$ test with the Pearson's correction or the Kruskal-Wallis test as appropriate. 